\title{
TRABALHO, EDUCAÇÃO E MOVIMENTO SOCIAL: ANÁLISE SOBRE O SABER E A ATUAÇÃO POLÍTICA DOS PESCADORES AFILIADOS À COLÔNIA DE Pescadores Artesanais Z-16 de Cametá/PA
}

\author{
EGÍDIO MARTINS \\ DORIEDSON DO SOCORRO RODRIGUES \\ AdenIL Alves RodRIGUES \\ Universidade Federal do Pará (UFPA), Belém, Pará, Brasil
}

\begin{abstract}
Resumo: Trabalho, Educação e Saberes dos Pescadores da Colônia Z-16 de Cametá - PA é produto de uma pesquisa que problematiza os saberes dos pescadores da Colônia Z-16 produzidos a partir do trabalho desses trabalhadores, buscando compreender como vem se dando a contribuição desses saberes quanto a fortalecê-los como sujeitos, assegurando a sobrevivência, ou negando o seu próprio trabalho. Na metodologia, pautou-se na abordagem qualitativa, do tipo estudo de caso, tendo como referência o materialismo histórico-dialético. Os pescadores desenvolvem seus saberes a partir do seu trabalho. A atuação política dos pescadores contribui para desenvolver o saber no e para o trabalho enquanto práxis produtiva.
\end{abstract}

Palavras-chave: Saberes do pescador. Trabalho e educação. Colônia de Pescadores Z-16. Movimento social.

INTRODUÇÃO

Trabalho, Educação e Saberes dos Trabalhadores da Colônia de Pescadores Artesanais Z-16 de Cametá-PA' é um estudo que busca investigar 
o saber dos pescadores ligados à Colônia de Pesca Z-16 de Cametá, construído no trabalho. Os saberes desses sujeitos, produzidos a partir do trabalho que realizam, vêm contribuindo para fortalecê-los como sujeitos, assegurando a sobrevivência? Ou esses saberes negam o seu próprio trabalho? Os pescadores encontraram na Colônia Z-16 um espaço para desenvolver seus saberes no trabalho, que possibilita a humanização, ou os trabalhadores encontram nessa entidade uma alternativa para adquirir os benefícios que a instituição tem conquistado perante o Estado, contradizendo a sua prática?

A categoria trabalho é central nesta investigação, visto que é através dele que o homem constrói relações, sem as quais seria impossível tornarse homem e construir a sociedade. O homem é o que é a partir da relação consigo mesmo, com a natureza e com o mundo (MARX, 2008). É no conjunto das relações sociais que o ser humano constrói o saber, produzido a partir do trabalho, inter-relacionado com o contexto social.

O saber está relacionado com a identidade, com a história, com o conhecimento e com a vida. Significa dizer que o saber também possibilita entender e discutir a construção da sociedade e refletir sobre ela, permitindose, inclusive, pensar uma sociedade na qual os trabalhadores tenham seus direitos garantidos, opondo-se à alienação do trabalho a que se encontram coagidos pela lógica sociometabólica do capital.

Discutir saber é favorecer a compreensão de como os trabalhadores realizam seus processos formativos, construindo-se enquanto sujeitos de uma práxis educativa que se busca contrária à negação de seus saberes, reconhecendo que a educação não se faz somente nos espaços escolares, já que muitas vezes esse espaço está mais preocupado com as atividades de leitura e escrita, sem as possibilidades de reflexão sobre a educação desenvolvida nos próprios processos de trabalho, como acontece com os pescadores da Colônia Z-16. A formação humana não pode ocorrer somente com a imersão do sujeito no societas rerum, de que nos fala Gramsci, dominando tão-somente os conhecimentos resultantes da produção humana no campo das ciências, mas com a inserção também no societas hominum, também tendo acesso aos conhecimentos relacionados a direitos e deveres na sociedade, numa perspectiva político-emancipatória (GRAMSCI, 1988).

O presente texto se insere numa abordagem qualitativa, do tipo estudo de caso, tomando como referência o materialismo históricodialético. Como instrumento de coleta de dados, apoiou-se na entrevista semiestruturada, objetivando: a) identificar como o saber dos pescadores da Colônia Z-16 é produzido a partir do seu trabalho; b) compreender a participação política dos pescadores no contexto do próprio movimento em que eles participam. 
Do ponto de vista estrutural, o texto se encontra dividido em quatros seções: a primeira reflete sobre a questão "Saberes dos trabalhadores: de onde partimos? Analisando as abordagens históricas e filosóficas que embasam os estudos sobre os saberes". Na segunda, faz-se uma análise sobre "o saber do trabalhador", refletindo as noções conceituais sobre os saberes. $\mathrm{Na}$ terceira, busca-se discorrer sobre "o saber construído a partir do sujeito nas relações sociais", destacando que o saber está articulado com a relação social. Finalmente, na quarta seção, faz-se uma análise da construção dos saberes, a partir das entrevistas realizadas junto aos trabalhadores da pesca. Por fim, expomos nossas considerações finais.

\section{SABERES DOS TRABALHADORES: DE ONDE PARTIMOS?}

Para Franco e Trein (2003), o estudo sobre o saber do trabalhador é um campo de discussão recente na área "trabalho e educação", surgindo a partir da necessidade da construção de um projeto de afirmação da realidade sob a perspectiva crítica e dialética, no sentido de superar o autoritarismo e, ao mesmo tempo, comprometer-se com as lutas dos trabalhadores.

Uma das preocupações centrais da discussão da área trabalho e educação é entender o trabalho como princípio educativo², ampliando a compreensão da formação humana e da sociedade para analisar a relação indissociável entre sociedade, trabalho e educação. Nessa relação, se insere o saber do trabalhador.

Saber do trabalhador como foco de pesquisa iniciou-se na França, no contexto da Sociologia do Trabalho, fazendo crítica ao sistema de produção taylorista ${ }^{3}$. Esse modelo de produção do fordismo-taylorismo tornou-se alvo de crítica desse tipo de sociologia, de modo a discutir como, nessa organização de trabalho, o saber do trabalhador é controlado, fragmentado, reduzido no processo de produção e impedido de manifestar a criatividade do próprio trabalhador. É nesse contexto que os estudos sobre o saber do trabalhador se ampliam, alcançando outra compreensão sobre o caráter formativo, o processo de trabalho, a qualificação, as práticas de resistência no trabalho, entre outros fatores ligados ao processo de trabalho.

A sociologia do trabalho francesa de trabalho friedmanniana, que se desenvolveu com o projeto de crítica com o irrealismo da reprodução do trabalho proposta pela racionalização tayloriana, enriquecida de aporte da economia e da ergonomia, tem grande influência na identificação do erro epistêmico que está na base de Organização Científica do Trabalho. Ela é incorporada para discutir a natureza dos saberes no trabalho, o estatuto da ciência e da técnica, o caráter formativo (ou deformativo) do trabalho, o processo de trabalho e a 
qualificação, as práticas de resistências à Organização científica do trabalho. Autores que fazem a crítica à divisão do trabalho e à determinação social da técnica são amplamente incorporados (SANTOS, 2003, p. 31).

As pesquisas em torno do saber do trabalhador têm grande influência com o desenvolvimento do processo de produção capitalista no contexto do fordismo-taylorismo. Segundo Harvey (2005), o fordismo-keynesianismo desenvolveu-se a partir de 1945 e se estendeu até 1973, período esse marcado por um conjunto de práticas de cunho tecnológico, político, social, entre outros. O fordismo se pautava nos princípios da administração científica de F. W. Taylor, que

Descrevia como a produtividade do trabalho poderia ser radicalmente aumentada através da decomposição de cada processo de trabalho em movimentos componentes e da organização de tarefas de trabalho fragmentadas segundo padrões rigorosos de tempo e estudo do movimento (HARVEY, 2005, p. 121).

Essa prática exercida no processo de produção da época provocou uma revolução no modo de produzir, foi a primeira vez que essa política foi desenvolvida no campo da produção. Um dos objetivos do fordismo, além de produzir em grande escala para um consumo de massa, era possibilitar, como menciona Harvey (2005), um novo tipo de sociedade democrática, que pudesse introduzir a modernidade tanto para os trabalhadores como para a sociedade.

As técnicas de trabalho do fordismo relacionavam-se não somente com um novo método de trabalho, mas com a maneira de ver, de pensar, de viver a vida. Isso demonstra que essa forma de produzir tinha um projeto ambicioso, capaz de revolucionar o pensamento da sociedade do período pósguerra. No entanto, ela chega ao colapso, a partir da década de 1970, e Harvey (2005) aponta duas situações que impediram a sua expansão. A primeira se enquadra na situação de classe que o mundo capitalista enfrentava: um cenário que dificilmente aceitaria uma política de produção, com rígido mecanismo de controle sobre os trabalhadores.

O fordismo enfrentou sérias críticas da sociedade, principalmente europeia, que viu na obra de Henri Faiol, publicada em 1916, Administration industrielle et générale, uma proposta de administração muito diferente daquela apresentada por Taylor. Harvey (2005, p. 123) assim destaca a importância da obra: mostrou-se um texto mais influente na Europa do que o de Taylor.

O segundo impedimento tem relação com o novo regulamento estatal: 
Foi necessário conceber um novo modo de regulamentação para atender aos requisitos da produção fordista; e foi preciso o choque da pressão selvagem e do quase-colapso do capitalismo na década de 30 para que as sociedades capitalistas chegassem a alguma nova concepção da forma e do uso dos poderes do Estado (HARVEY, 2005, p. 124).

Para superar a crise de um sistema de produção colocado em risco, o sistema capitalista, o fordismo se apoia no keynesianismo, tomando como base de sustentação o Estado e abrindo espaço para novos elementos no campo da produção. O Estado, no entender de Harvey (2005), concentrou esforços no sentido de garantir infraestrutura para segurar o processo de produção, objetivando sua ampliação e o consumo de massa.

Esses fatores contribuíram para a derrocada da produção fordista, dando início, a partir de 1970, à segunda fase do modo de produção capitalista, ou uma transição, nas palavras de lanni (1994), apoiada num outro modo de produção que Harvey (2005) identifica como "acumulação flexível", cujo marco é o confronto com a rigidez do fordismo.

A flexibilização no processo de produção requer novas técnicas, mão de obra preparada para produzir com quantidade e qualidade para atender ao mercado de trabalho, de acordo com a necessidade do consumidor. A acumulação flexível se estrutura por meio de um conjunto de elementos que possibilitam sua materialidade. São eles: flexibilidade do processo de trabalho, mercado de trabalho, produção e padrão de consumo. Tem como característica o surgimento de setores de produção, novas maneiras de fornecimento, de serviços financeiros, novos mercados, taxas altas de intensificação de inovação comercial, tecnologia e organização no processo de produção.

Essa estrutura que vem sendo articulada em torno do processo de produção flexível tem a intenção de reduzir os postos de trabalhos nas fábricas, e, ao mesmo tempo, torná-los mais flexíveis nos momentos em que a situação não estiver contemplando as exigências do processo de produção. Trata-se de um modo de produção articulado no contexto do sistema capitalista que Harvey (2005) referenda como uma forma de organização para fortalecer a circulação do capital econômico.

É nesse contexto que se fortalece a discussão em torno do saber do trabalhador, iniciada, como aqui já mencionado, na França, fazendo crítica ao fordismo-taylorismo, em seguida à flexibilidade do processo de trabalho. Essa vertente de pesquisa ancorada no campo do trabalho e da educação chega ao Brasil a partir dos anos 1990. Assim, o saber do trabalhador tornouse uma preocupação dos estudiosos críticos dessa temática. 


\section{O SABER DO TRABALHADOR}

O saber dos pescadores é uma singularidade, em que somente eles constroem uma linguagem própria a partir do trabalho e sobre o trabalho de suas ações. Para Pereira e Aranha (2006, p. 106), “[...] trabalho é criação, aprendizagem, desenvolvimento, dominação e aquisição de saberes". Ou seja, pelo trabalho, o homem produz saberes, que dão conta de uma unidade teórico-prática, em que ação-pensar se realizam concomitantemente.

Os saberes dos trabalhadores da Colônia Z-16 são articulados a partir do trabalho, de modo que este proporciona aos trabalhadores aprenderem e ao mesmo tempo ensinarem outros trabalhadores nas diversas situações de sua profissão. Esses sujeitos se organizam também em torno de um movimento capaz de fortalecer suas lutas em prol de suas realizações. Para Arroyo (1995, p. 79), o "[...] movimento enquanto prática, enquanto práxis social, traz em si uma revolução no saber, no reconhecer-se, educar-se e formar-se das classes".

O saber construído a partir do trabalho dos pescadores possibilita um conjunto de relações sociais e, nessas relações, os pescadores aprendem, desenvolvem uma cultura singular, um saber caracterizado por uma linguagem produzida no trabalho. Assim, nesse conjunto de ações, se educa.

Para Marx, então, o fundamento da história é a atividade humana, a práxis humana e o trabalho. $\mathrm{O}$ ser social produz linguagem, consciência, cultura, produz a si mesmo, portanto, através de sua práxis e do seu trabalho. Com efeito, se as relações sociais são a essência genética do homem; se a linguagem e consciência são mediadoras de toda a práxis, além de serem produtos dela; se o trabalho é atividade que produz materialmente a própria vida; e se o homem é um ser que se constrói no conjunto das relações, num movimento constante, num processo infinito, então não há como recusar o caráter educativo imanente a toda a história do homem (SOUSA JUNIOR, 2010, p. 23-24).

A construção do saber é produto da práxis social. É um saber que contribui para a constituição do trabalhador, porque possibilita a formação de uma concepção de mundo e, ao mesmo tempo, questiona o todo social. Conforme Arroyo (1995, p. 79), "No permanente movimento social pela construção de uma sociedade alternativa, vão se construindo um conjunto de práticas e de concepções sobre o todo social que questiona e desafia as práticas e concepções hegemônicas".

Arroyo (1995, p. 81) defende ainda que o saber dos trabalhadores é negado, esquecido no seu próprio lócus de trabalho: "é um movimento de negação da legitimidade dos trabalhadores do saber de gente comum, e de 
negação da legitimidade dos trabalhadores enquanto produtores de saber e de cultura". Esse saber não interessa à classe dominante, porque questiona as práticas da burguesia, que luta para manter seu poder perante a sociedade. No campo educacional, essa luta fica explícita, principalmente, quando se percebem as estruturas que historicamente as escolas têm, o que as faz o único espaço de construção dos saberes, negando dessa forma os outros saberes construídos em outros espaços da sociedade, como nos movimentos sociais.

[...] conceber, por exemplo, "formação de adultos", "formação profissional" sem interrogar sobre o que os "formandos" já construíram como saber em seu trabalho, e como esse trabalho sobre suas próprias competências inscreve-se em projetos de vida, é contentar-se com uma certa esterilidade do ato educativo [...]"afirmar o movimento como princípio educativo da formação dos'sem terra'é considerar que seu processo educativo básico está no próprio movimento, no 'transformar-se a si mesmo, transformando a terra' (SCHWARTZ, 2003, p. 29).

Os saberes dos trabalhadores são desenvolvidos também nos espaços dos movimentos sociais. Nesse sentido, a luta contribui para legitimar o processo de construção de saberes, qualificando, valorizando o trabalhador, o seu espaço, o seu saber e manifestando-se como uma forma de compreender e lutar pela garantia de suas condições de vida. O pescador é um sujeito que desenvolve seus saberes no trabalho, nas relações sociais, nas relações consigo mesmo.

\section{O SABER DO TRABALHADOR CONSTRUÍDO NAS RELAÇÕES SOCIAIS}

O saber não se constrói por si só, mas nas relações do sujeito com o mundo. Nessa relação se produz aprendizagem. Aprendizagem é uma relação entre o sujeito e o mundo, uma relação de significado, de sentido, de construção do sujeito, em outras palavras, da cultura. Aprender é construir uma história, é desenvolver um conjunto de relações entre o sujeito e o mundo. Aprender é tornar-se homem.

Por isso mesmo, nascer significa ver-se submetido à obrigação de aprender. Aprender para construir-se, em um triplo processo de "hominização" (tornar-se homem), de singularização (tornar-se membro de uma comunidade, partilhando seus valores e ocupando um lugar nela). Aprender para viver com os outros homens com quem o mundo é partilhado. Aprender para apropriar-se do mundo, de uma parte desse mundo, e para participar de construção de um mundo pré-existente. Aprender em uma história que é, ao mesmo tempo, profundamente minha, no que tem de única, mas que 
me escapa por toda a parte. Nascer, aprender, é entrar em um conjunto de relações e processos que constituem um sistema de sentido, onde se diz quem eu sou, quem é o mundo, quem são os outros (CHARLOT, 2000, p. 53).

O saber requer a presença do sujeito, o qual requer a presença do saber para estabelecer uma relação com o mundo, uma relação construída em diversos espaços da sociedade. Por isso, a aquisição do saber não advém apenas do espaço escolar, mas de outros espaços, como do trabalho.

[...] qualquer tentativa de definir o saber faz surgir um sujeito que mantém com o mundo uma relação mais ampla. Uma das consequências desse raciocínio é o de que o saber não advém apenas do espaço escolar, caracterizado como um espaço de trabalho com o saber formalizado. Mas também de outros espaços, como o profissional, familiar, social, cultural (PEREIRA; ARANHA, 2006, p. 104).

Os sujeitos do presente estudo (os pescadores) estão envolvidos num movimento social que engloba o trabalho, o contexto social e a cultura, ou seja, são trabalhadores que buscam espaços de legitimação de seus saberes, através do movimento em que participam, relacionando-se consigo mesmo, com a sociedade e com o mundo. A organização dos pescadores tem proporcionado um espaço de discussão, de planejamento de luta, em momentos que, acrescidos de outros momentos, desenvolvem os saberes desses trabalhadores, sempre incompletos, mas presentes nas relações no cotidiano desses trabalhadores.

[...] pensar as relações educativas remete a uma rede de processos e relações sociais encarnadas em sujeitos singulares e tecidas em torno de um precioso objeto: o saber, sempre incompleto, mobilizador do desejo de saber que, por sua vez, pode se apresentar como desejo de não saber (SANTOS; DINIZ, p. 144).

O processo educativo, como rede de relações que Arroyo (2002) defende, ultrapassa a escola. São as relações sociais construídas entre sujeitos, homens e mulheres que, ao longo de suas vidas, de sua trajetória de vida, vão construindo saberes, produtos também da relação com o mundo. Não se pode negar que a construção do saber é produto da relação social desenvolvida ao longo da história, somente na e pela história os saberes são construídos, aperfeiçoados, vivenciados. Para Schwartz (2003, p. 25): "toda atividade de trabalho encontra saberes acumulados nos instrumentos, nas técnicas, nos dispositivos coletivos, toda a situação de trabalho está saturada de normas de vida, de formas de exploração da natureza e dos homens uns pelos outros". 
O saber é resultante da materialidade histórica do sujeito, está contido nele, na sua ação, no seu trabalho, de modo que o homem necessita do saber para dar conta de sua existência. O homem na sua relação social não aprende de forma isolada, mas na relação com o outro e com a natureza. O ser humano é o que é no processo de construção histórico. Marx (1988) menciona que a natureza humana se reduz com as atividades específica, repetitivas, faz-se do homem um ser automático, com pouca criatividade, qualificado apenas naquela função. Sua característica de trabalhador, construtor da história, se limita.

A construção do saber do trabalhador não é limitada e fragmentada; ao contrário, é desenvolvida ao longo da vida através do trabalho, da relação do homem consigo mesmo e com a natureza. A construção dos saberes se pauta na relação entre o saber e o sujeito, uma relação que se desenvolve no processo de organização das relações internas, o que implica dizer que ela requer a presença do sujeito na sua atividade num processo de relação com outros.

[...] não há saber senão para um sujeito, não há saber senão organizado de acordo com as relações internas, não há saber senão produzido em uma "confrontação interpessoal". Em outras palavras, a ideia de saber implica a de sujeito, de atividade do sujeito, de relação do sujeito com ele mesmo (deve desfazer-se do dogmatismo subjetivo), de relação desse sujeito com os outros (que constroem, validam, partilham esse saber) (CHARLOT, 2000, p. 61).

Schanger (1978 apud CHARLOT, 2000, p. 62) diz que "saber é relação", que envolve necessariamente sujeito e mundo, antes de o sujeito construir uma relação com o saber; primeiro ele se relaciona com o mundo e essa relação é mais ampla do que a relação com o saber. Charlot (2000, p. 59) destaca que "o saber faz surgir um sujeito que mantém com o mundo uma relação mais ampla do que a relação do saber".

Para conceituar o saber, se faz necessária uma distinção entre o saber e o conhecimento. Parecem dois termos iguais, mas apresentam diferenças. $\mathrm{O}$ conhecimento se articula numa sistematização mais formal, é produzido com mais rigor, enquanto o saber se articula em âmbito não formal, construído no processo de trabalho e em outros espaços.

Não se encontram, facilmente, estudos e investigações que privilegiem a concepção de saber numa perspectiva mais ampla. Preferimos, neste texto, convocar a palavra "saber" no lugar do conhecimento, a despeito da conotação pejorativa que comumente se reveste, por dois motivos. Primeiro porque a forma substantiva "saber" é mais ampla do que a forma substantiva "conhecimento", entendido como já formalizado e legitimado, saber 
objetivante que circula no nível da consciência. Além disso, "saber" supõe a forma verbal que implica tomá-lo não só como produto, e não só como produto social e historicamente formalizado segundo cânones instituídos, mas, também, e ao mesmo tempo, "saber" como ato, processo. Logo como relação de alguém com alguma coisa que, em última instância, é relação de alguém consigo mesmo (SANTOS; DINIZ, 2003, p. 143).

Outro elemento que envolve o conceito de saber é o "sujeito", de modo que a existência do saber requer a existência de alguém que sabe e, ao mesmo tempo, está em processo de saber como algo provisório, constantemente em construção.

Os textos em educação normalmente usam os termos conhecimento e saber sem distinção de significado. Reconhecendo que nem os filósofos possuem uma posição clara sobre a diferenciação de significado desses termos, nós... usaremos ambas as denominações sem diferenciação rígida, embora tendamos a diferenciá-las da seguinte forma: conhecimento aproximar-se-ia mais com produção científica sistematizada e acumulada historicamente com regras mais rigorosas da validação tradicionalmente aceitas pela academia; o saber, por outro lado, representaria um modo de conhecer-saber mais dinâmico, menos sistematizado ou rigoroso e mais articulado a outras formas de saber e fazer relativos não possuindo normas rígidas formais de validação (FIORENTINl; SOUZA; MELO, 1998, p. 312 apud ZAIDAN, 2003, p. 87).

O processo de construção de saber não é rígido, mas construído na dinâmica do homem consigo mesmo e com os outros no ambiente de trabalho; já o conhecimento se propaga em âmbito sistematizado, organizado. Para Zaidan (2003), seria difícil estudar o conhecimento dos trabalhadores, que vivem diretamente nos movimentos sociais, uma vez que, para essa autora, o conhecimento está mais vinculado ao espaço acadêmico.

O saber é um processo de relação que se desenvolve no âmbito coletivo e pessoal, um processo construído na relação de trabalho, na prática do sujeito, envolvendo as emoções, as afetividades, as histórias de cada um e do coletivo de forma interdependente.

Compreende o conceito de saber como sendo evolutivo e cultural porque pessoal /relacional/contextual, podendo modificar-se com o tempo e a experiência, portanto provisório. O saber é estruturado sem deixar de estar constantemente em construção, constituindo-se de sistemas como conjuntos de elementos interdependentes. É afetivo porque relaciona-se com os sujeitos, a construção dos sujeitos, suas auto-imagens, julgamentos, sentimentos (ZAIDAN, 2003, p. 84). 
O saber é construído na relação do trabalhador no ambiente de trabalho, ou seja, é construído pelo sujeito. É uma relação que proporciona comunicação, disponível para outros. O saber é provisório, de modo que está sempre em construção. Não há um saber fechado, dogmático, mas sim dinâmico e em ação.

\section{OS SABERES dOS PESCADORES dA ColÔNIA Z-16 E SUAS RELAÇÕES COM O TRABALHO}

As aprendizagens dos pescadores da Colônia Z -16 são produto de suas atividades, configurando-se como saberes produzidos no contexto de suas relações sociais, tal como preconiza Charlot (2000). Isso acontece de modo que o processo de aprendizagem dos trabalhadores da pesca se materializa no contexto histórico de suas relações com os seus familiares, com a natureza e com os outros trabalhadores.

Os pescadores vêm construindo saberes a partir das atividades desenvolvidas no seu trabalho. Mas essas realidades vêm nos últimos tempos sofrendo impacto das influências dos saberes controlados pelo capital, de modo que os pescadores têm introduzido, nas atividades de pesca, instrumentos industrializados, como fica evidente na fala do informante a seguir:

Para o meu pai tecer uma malhadeira ele comprava fibra e ia tecer, fazia malhadeira com quinze metros, vinte metro, para pegar o peixe, agora não, agora você vem na loja compra o material que você quiser para pescar, a malhadeira já vem até intralhada, ou seja, pronta para o uso, tem pescador que malha, malha, malha com a rede, quando já não presta mais, já está só buraco, joga fora, não vai consertar, prefere comprar outra.(P $\left.4^{4}\right)$

Assim, o pescador está lentamente deixando de construir seus instrumentos de trabalho, começando a depender dos produtos fabricados por um saber controlado pelo capital. A classe que controla esse capital busca somente acumular lucros. Assim, trata-se de um saber que detém o controle de todo o processo da produção e que, nessa lógica, vale o que traz rentabilidade para o capital. A fala do sujeito acima entrevistado demonstra que a lógica de uma ideologia impregnada com saber de uma classe que detém o controle da produção está cada vez mais presente nos trabalhos dos pescadores da Colônia Z-16.

O saber dos pescadores está inter-relacionado ao contexto das atividades de seu trabalho e das relações históricas que constroem de geração em geração. Entende-se por atividade toda a base da construção humana ou as atividades que proporcionam os elementos para assegurar a vida 
humana. O trabalho tem um papel fundamental no processo de construção dos saberes dos trabalhadores da pesca, de modo que as aprendizagens desses trabalhadores acontecem nas vivências com seus pares pelo trabalho.

[...] eu acho que foi dos quinze anos já ia com o meu pai pilotar, remar, jogar rede, e de lá eu acho que não teve mais pai, da pesca eu sei de tudo, sei fazer malhadeira, eu sei fazer matapi, eu sei fazer tarrafa [...] (P 4).

É a ação humana o elemento de intermediação de construção do próprio homem; a sua maneira de agir, de pensar, de se relacionar constitui um conjunto de fatores subjetivos mediados pelo trabalho. Para Severino (1998, p. 33), "[...] o agir é a mediação construtora do ser do homem. Para falar do homem, não há como abordá-lo com base em sua essência, mas necessariamente em seu agir". Quando o pescador menciona que "da pesca sabe de tudo", significa que tem domínio de suas atividades, ou melhor, construiu um saber a partir da vivência, da experiência, da relação com o seu ambiente de trabalho e com os outros pescadores.

O saber do trabalhador da colônia é produto da relação social e historicamente estabelecida, de modo que a aprendizagem vai se construindo no seio de uma relação no trabalho. Em uma das entrevistas realizadas, foi perguntado se era difícil construir o instrumento de pesca e uma das falas demonstrou que

Não, não foi difícil porque eu acho que foi a partir de doze, quatorze anos que o meu pai comprou a primeira malhadeira, daí eu foi prestando atenção no momento que ele ia concertar quando rasgava, prestava atenção, quando ele ia tecer um matapi, quando ia tecer uma tarrafa e eu tava lá perto, aprendi e não tive dificuldade, foi fácil, muito fácil memo. Hoje eu já ensino para outras pessoas, para meus filhos, têm pessoas que vêm comigo pedir para ensinar fazer uma cabeça de tarrafa, eu começo a fazer a cabeça de tarrafa para ele, eu digo: é assim cada carreira de filho você não pode passar para outra malha, você tem que levar até no pé da tarrafa, então a pessoa que presta atenção em poucos dias aprende mesmo (P 4).

Essa fala justifica a afirmação de Charlot (2000, p. 70), para quem "aprender então é dominar uma relação, de maneira que, nesse caso também, o produto do aprendizado não pode ser automatizado, separado da relação em situação".

Assim, se pode dizer que os pescadores produzem seus saberes e que essa produção faz parte de um processo que requer experimentação, análise, reflexão, esforço e dedicação para com suas atividades. Nessa relação, o pescador ultrapassa a circunstância do próprio trabalho, produzindo um 
saber que, ao mesmo tempo, é produto de sua relação no trabalho, contribui para avançar em sua condição de existência, e esta, por sua vez, justifica a expressão de Nunes (2002, p. 447), de que "[...] a existência do homem só pode ser aprendida em suas mediações históricas e sociais".

Com os trabalhadores da Colônia Z-16, encontramos uma forma de atividade desenvolvida por eles mesmos, a pesca, que parece simples de ser praticada; no entanto, apresenta um contexto amplo de significados, porque está envolvido num conjunto de elementos que proporciona a relação com o seu mundo. Como frisa Charlot (2000), o mundo é para o homem a partir do que ele imagina, do que cria, pensa e se relaciona com ele, um mundo de significados que proporciona a relação com os outros. Existe atividade de pesca que envolve um conjunto de relações, tanto de pessoas como de materiais.

Rede aberta é a rede que pega o mapará, que bloqueia o cardume do peixe, vamos dizer o Assilo é dono de uma rede aberta, ele bloqueia o mapará, ou seja, cerca um cardume do peixe, depois de cercado bate água para o mapará bater na rede, é isso que se chama de rede aberta, é uma espécie de pescaria, para pegar o peixe em quantidade. Numa rede aberta trabalha em torno de dez a doze pessoas, em dois cascos, agora tem o taleiro que ocupa quatro pessoas, tem as pessoas que vão para bater água, essa pescaria utiliza uma base de vinte pessoas, porque é muito peixe, pega-se de peneiros cheiros de peixes (P 4).

Nessa modalidade de pesca, há um conjunto de atividades que os pescadores desenvolvem; começa com um pescador experiente, que identifica através de uma tala onde está o cardume do peixe; identificado o cardume, vem o grupo de pescadores para fazer o cerco com a rede; após o peixe ser cercado, alguns pescadores vão bater água para que ele fique preso na malhadeira; outros trabalhadores, por sua vez, ficam no casco para ajudar colocar a rede com o peixe no casco. É essa modalidade de pesca que se chama rede aberta, é a pesca do mapará (hipophytalmus marginatus), um peixe típico da região amazônica.

Nessa pescaria, se observa o saber específico do pescador, de modo que essa atividade somente se encontra na profissão de pescador. Uma atividade que também é social, porque necessita da colaboração de um conjunto de trabalhadores. Isso sem descartar o processo de comercialização e a forma como cada trabalhador será beneficiado com a produção. Este é um dos saberes que vem passando de geração em geração entre os trabalhadores da pesca.

Quando o pescador menciona que aprendeu através das atividades, está confirmando a sua existência através do trabalho. Dessa maneira, os pescadores constroem saberes através das atividades, tendo como resultado 
ou produto o próprio saber do trabalhador, de modo que esse saber assegura sua existência. O saber não é o fim, mas parte de um processo que se articula como círculo, homem, atividade, finalidade, que é o saber produzido, para novamente começar pela atividade do trabalho e garantir a vida.

Para Vázquez (1977, p. 192), “o homem age conhecendo, do mesmo modo que [...] se conhece agindo. O conhecimento humano em seu conjunto integra-se na dupla e infinita tarefa do homem de transformar a natureza exterior e sua própria natureza". O saber produzido através do trabalho necessita de uma mediação; essa mediação são os instrumentos que os pescadores utilizam em seu trabalho de pesca; os instrumentos desse trabalho são diversos, entre eles a malhadeira, o matapi, a tarrafa, a rede aberta, o casco, o remo, entre outros. Sobre isso, Vázquez (1977), ao tratar sobre práxis produtiva, entende que os instrumentos modificam o tipo de relação existente entre o homem e a natureza. Os instrumentos que os pescadores utilizam são produtos de sua construção, desenvolvidos no processo de construção histórica.

[...] o saber não existe de forma autônoma, pronto e acabado, mas é síntese das relações sociais que os homens estabelecem na sua prática produtiva em detrimento do momento histórico. Assim o trabalho compreendido como todas as formas de atividades humanas pelas quais o homem aprende, compreende e transforma as circunstâncias ao mesmo tempo em que se transforma é a categoria que se constitui no fundamento do processo de elaboração do conhecimento (KUENZER, 1989, p. 183).

O saber do trabalhador da pesca é um produto da relação social historicamente estabelecida, uma vez que a aprendizagem é construída no seio de uma relação humana a partir do trabalho. Ou seja, o saber do pescador está relacionado com sua história de vida, com sua maneira de trabalhar, de se relacionar com seus pares e com os instrumentos de seu trabalho. Fazer essa distinção entre saber e trabalho não é tão fácil, porque o pescador aprende trabalhando para melhorar o seu trabalho e sua vida. Nesse sentido, esclarecedoras são as colocações feitas pelo informante (P 4).

[...] foi com o meu pai, se ele pulava pra ir jogar uma malhadeira no rio, eu pulava junto com ele, se ele pulava pra fazer uma tapagem para pegar o camarão, eu pulava junto com ele, aí eu foi aprendendo, hoje eu sei fazer tudo isso, tou com cinqüenta anos, aprendi tudo isso com ele, com a minha mãe e com o meu pai.

Os pescadores da Colônia Z-16 constroem seus saberes no contexto de seus trabalhos, também numa relação de contradição, considerando que, 
ao mesmo tempo em que os pescadores constroem seus instrumentos, objeto de intermediação com a natureza e com os outros, os objetos são também fabricados por outros saberes controlados pela classe que detém o poder aquisitivo.

E é nesse jogo de contradições que vão emergindo saberes, frutos das materialidades desenvolvidas pelos trabalhadores, a partir das mediações proporcionadas pelo trabalho. São saberes que constituem aspectos da identidade desses sujeitos, corroborando processos de luta contra as ações do capital e objetivando reconfigurar a existência dos trabalhadores da pesca. Nesse contexto, esses sujeitos se impõem pela materialização de seus interesses, por meio de saberes que lhes fortalecem a existência política, social, econômica e cultural.

\section{CONSIDERAÇÕES FINAIS}

O presente estudo buscou refletir sobre os saberes dos trabalhadores da Colônia Z-16 produzidos a partir dos seu trabalho, procurando compreender a participação política desses sujeitos no contexto do seu movimento social e relacionando o saber existente nas suas relações sociais com as ações dos pescadores e com o mundo.

As conclusões destacam que os trabalhadores da Colônia Z-16 constroem saberes no contexto de seu trabalho, articulado com o contexto social. No trabalho dos pescadores, um conjunto de elementos se articula, entre eles a educação, o trabalho, a cultura e a participação política, em diversos eventos relacionados à profissão, que possibilitam a construção dos saberes.

O saber do pescador está inserido num contexto social, de modo que, no processo de desenvolvimento do trabalho, outra realidade se articula e mantém-se inter-relacionada a esse fazer. O pescador é um trabalhador que constrói um ambiente de vida particular e, nesse espaço, especialmente no contexto familiar, desenvolve a cultura e a educação em torno do trabalho. Ficou evidente também que esses saberes são desenvolvidos pelos pescadores, ao longo de um processo histórico. A construção do saber requer a relação do trabalhador consigo mesmo, com o trabalho e com o mundo, para refletir a realidade rumo às transformações. 
LABOR, EDUCATION AND SOCIAL MOVEMENT: ANALYSIS OF THE KNOWLEDGE AND POLITICAL ACTION OF FISHERMEN AFFILIATEDTO COLONY OF ARTISAN FISHERMEN Z-16 OF CAMETÁ-PA

AвSTRACT: Work, Education and Knowledge of the fishermen of the Z-16 Colony of Cametá-Pa is the product of a research that problematizes the knowledge of the fishermen of the Colony Z-16 produced from the work of these workers, trying to understand how the contribution has been given Knowledge to strengthen them as subjects, ensuring survival, or denying their own work. In the methodology was based on the qualitative approach, of the type of case study, having as reference the historical-dialectical materialism. Fishermen develop their knowledge from their work. The political activity of fishermen contributes to the development of knowledge in and for work as a productive praxis.

KEYWORDS: Fisherman's knowledge. Work and education. Fishermen's Colony Z-16. Social movement.

TRABAJO, EDUCACIÓN Y MOVIMIENTO SOCIAL: ANÁLISIS DEL SABER Y LA ACTUACIÓN POLÍTICA DE LOS AFILIADOS A LA COLONIA DE PESCADORES ARTESANOS Z-16 CAMETÁ-PA

Resumen:Trabajo, Educación y Saberes de los pescadores de la Colonia Z-16 Cametá-Pa, es fruto de una investigación que cuestiona los saberes de los pescadores de la Colonia Z-16, producido a partir de la labor de esos trabajadores, intentando comprender cómo se está desarrollando la contribución de esos saberes con la intención de fortalecerlos como sujetos, garantizando la supervivencia o negación de su trabajo. La metodología se basa en el enfoque cualitativo, del tipo estudio de caso, tomando como referencia el materialismo histórico y dialéctico. Los pescadores desarrollan sus saberes a partir de su trabajo. La actuación política de los pescadores contribuye para desarrollar el saber y para el trabajo como una práctica productiva.

Palabras Clave: Saberes del Pescador. Trabajo y Educación. Colonia de pescadores Z-16. Movimiento social.

\section{NOTAS}

1. Embora o termo colônia possa suscitar a imagem de um coletivo de pescadores vivendo da pesca à margem de um rio, a Colônia de Pescadores Artesanais Z-16 é bem mais que isso. "Ela se constitui na entidade representativa de classe [dos sujeitos pescadores do município de Cametá-Pa], reunindo [...] associados de diferentes comunidades do município [...], com sede na Travessa Porto Pedro Teixeira, n 165, 
bairro de Brasília, cidade de Cametá. Sua fundação data de 1923" (BARRA, 2004, p. 31). Destaque-se que a presente pesquisa foi desenvolvida a partir da Colônia de Pescadores Artesanais Z-16, presente no município de Cametá, situado na região Nordeste. Segundo o Instituto Brasileiro de Geografia e Estatística - IBGE (2007), o município de Cametá apresenta uma população de 120.896 habitantes, dentre os quais 52.838 habitantes encontram-se na zona urbana e 68.058 estão na zona rural. Em termos percentuais, $56,29 \%$ da população é rural, enquanto $43,71 \%$ é urbana. Ou seja, um grande percentual da população cametaense reside nas ilhas e no setor de estradas, que acabam, não raro, constituindo a zona rural do município cametaense.

2. O trabalho, para Gramsci, é essencialmente um elemento constitutivo do ensino, semelhante ao que é o aspecto prático no ensino tecnológico em Marx; o trabalho não é um termo antagônico e complementar do processo educativo, ao lado do ensino em suas variadas formas, mas se insere no ensino pelo conteúdo e pelo método. Enquanto em Marx, em suma, ocorre principalmente a integração do ensino, ainda que dotado de plena autonomia e riqueza de conteúdo, no processo de trabalho de fábrica, em Gramsci, ocorre a integração do trabalho como momento educativo no processo totalmente autônomo e primário do ensino (MANACORDA, 1991, p. 135).

3. Os Princípios de Administração Científica, de F. W. Taylor - um influente tratado que descrevia como a produtividade do trabalho podia ser radicalmente aumentada através da decomposição de cada processo de trabalho em movimentos componentes e da organização e tarefas de trabalho fragmentadas segundo padrões rigorosos de tempo e estudo do movimento [...] (HARVEY, 2005, p. 121).

4. Neste trabalho, o código (P) refere-se a pescador. O número indica ser um pescador distinto de outro pescador.

\section{REFERÊNCIAS}

ARROYO, M. G. O direito do trabalhador à educação. In: GOMES, C. M. (Org.) Trabalho e conhecimento: dilema do trabalhador. 4. ed. São Paulo: Cortez, 2002.

ARROYO, Miguel G. O Direito do Trabalhador à Educação. In: GOMES, Carlos Minayo. (Org.) Trabalho e conhecimento: dilema do trabalhador. 3. ed. São Paulo: Cortez, 1995.

BARRA, J. D. F.; Furtado, GISLENE, Damasceno. Pescadores Artesanais de Cametá: Formação Histórica, Movimentos e Construção de Novos Sujeitos, Cametá - Pará, 2004.

CHARLOT, B. Da relação com o saber: elementos para uma teoria. Porto Alegre: Artes Médicas, 2000.

FRANCO, M. C.; TREIN, E. O percurso teórico do GT Trabalho e Educação: uma análise para debate. Revista Brasileira de Educação, Rio de Janeiro, n. 24, set-dez/2003.

GRAMSCI, A. Os intelectuais e a organização da cultura. São Paulo: Civilização Brasileira, 1988. 
HARVEY, David. Condição pós-moderna. São Paulo: Loyola. 2005.

IANNI, O. O mundo do trabalho. Revista São Paulo em Perspectiva, São Paulo, v. 8, n. 1, jan./mar.1994.

IBGE. Instituto Brasileiro de Geografia e Estatística. Contagem da População 2007. Disponível em: < http://www.ibge.gov.br/home/estatistica/ populacao/contagem2007/ default.shtm>. Acesso em: 25 mar. 2010.

KUENZER, A. Z. Pedagogia da fábrica: as relações de produção e a educação do trabaIhador. São Paulo: Cortez: Autores Associados, 1989.

MANACORDA, M. A. A pedagogia marxista na Itália: Antonio Gramsci. In: Marx e a pedagogia moderna. São Paulo: Cortez, 1991.

MARX, K. Posfácio da 2a edição. In: O capital $\square$ Crítica da economia política. 12 ed. Rio de Janeiro: Bertrand Brasil, 1988. (Livro 1, vol. 1)

.O capital: crítica da economia política. Rio de Janeiro: Civilização Brasileira, 2008. (Vol. 1)

NUNES, R. A filosofia e o filosofar. In: PIOVESAN, A. Filosofia e o ensino em debate. ljuí, RS: Unijuí, 2002.

PEREIRA, Rosângela Maria; ARANHA, Antônia Vitória Soares. O saber das costureiras faccionistas da indústria de confecção de Divinópolis. Trabalho \& Educação. Belo Horizonte, n. 15, p. 101-114, , jun, 2006.

SANTOS, E. H.; DINIZ, M. O sujeito, o saber e as práticas educativas. Trabalho \& Educação, Belo Horizonte, n.1, p. 137-150, jun./2003.

SANTOS, E. H. Processo de produção e legitimação de saberes no trabalho. In: GONÇALVES, L. A. O. (Org). Currículo e políticas públicas. Belo Horizonte: Autêntica, 2003.

SEVERINO, A. J. O conhecimento pedagógico e a interdisciplinaridade: o saber como intencionalização da prática. In: FAZENDA, I.C. Arantes (Org). Didática e interdisciplinaridade. São Paulo: Papirus, 1998.

SCHWARTZ, Y. Trabalho e saber. Trabalho \& Educação, Belo Horizonte, n. 1, p. 21-34, jun./2003.

SOUSA JUNIOR, J. de. Marx e a crítica da educação: da expansão liberal-democrática à crise regressivo-destrutivo do capital. Aparecida, SP: Ideias \& Letras, 2010.

VÁZQUES, A. S.. Filosofia da práxis. 2. ed. Rio de Janeiro: Paz e Terra, 1977.

ZAIDAN, Samira. Saberes experienciais e saberes pedagógicos: um estudo. Revista Trabalho \& Educação, Núcleo de Estudos sobre Trabalho e Educação, v. 12, n. 1, jan./ jun. 2003. 
Egídio Martins: Doutorando do Programa de Pós-graduação em Educação (PPGED-UFPA), da linha de pesquisa Políticas Públicas Educacionais do Instituto de Ciências da Educação (ICED-UFPA). Membro do Grupo de Estudos e Pesquisas sobre Trabalho e Educação (GEPTE/ UFPA). Docente da Universidade Federal do Pará.

E-mail: egidio@ufpa.br

Doriedson do Socorro Rodrigues: Coordenador do Campus Universitário do Tocantins/Cametá. Membro do Grupo de Estudos e Pesquisas sobre Trabalho e Educação (GEPTE/UFPA). Docente do Programa de Pós-Graduação em Educação/UFPA.

E-mail: doriedson@ufpa.br

Adenil Alves Rodrigues: Mestre em Políticas Públicas Educacionais pelo Instituto da Ciência da Educação da Universidade Federal do Pará. Membro do Grupo de Estudos e Pesquisas sobre Trabalho e Educação (GEPTE/UFPA).

E-mail: adenil2007ufpaa@yahoo.com.br 